\title{
Correction to: Health care providers' support of patients' autonomy, phosphate medication adherence, race and gender in end-stage renal disease
}

\author{
Ebele M. Umeukeje ${ }^{1,2} \cdot$ Joseph R. Merighi $^{3}$. Teri Browne ${ }^{4} \cdot$ Marcus Wild $^{1,2}$. \\ Hafez Alsmaan ${ }^{5}$ Kausik Umanath ${ }^{5}$. Julia B. Lewis ${ }^{1,2} \cdot$ Kenneth A. Wallston $^{6}$. \\ Kerri L. Cavanaugh ${ }^{1,2}$ (1)
}

Published online: January 8, 2019

(C) Springer Science+Business Media, LLC, part of Springer Nature 2019

\section{Correction to: \\ J Behav Med (2016) 39:1104-1114 \\ https://doi.org/10.1007/s10865-016-9745-7}

In the original publication of the article, the majority of changes stem from misclassification of "medium adherence" when using the Morisky Medication Adherence Scale (MMAS-8) and not using the correct scoring algorithm for one of the responses when calculating MMAS-8 total scores.

The changes are organized based on their order of appearance in the article. To ensure that the findings reflect the accurate use of the MMAS- 8 , the authors verified the original data, re-ran all statistical analyses, and highlight below all changes needed with regard to the MMAS- 8 in the text and tables.

The original article can be found online at https:// doi.org/10.1007/s10865-016-9745-7.

Kerri L. Cavanaugh

kerri.cavanaugh@vanderbilt.edu

1 Division of Nephrology and Hypertension, Vanderbilt University Medical Center, 1161 21st Avenue MCN S-3223, Nashville, TN 37232, USA

2 Vanderbilt Center for Kidney Disease, Nashville, TN, USA

3 School of Social Work, University of Minnesota, Saint Paul, MN, USA

4 College of Social Work, University of South Carolina, Columbia, SC, USA

5 Division of Nephrology and Hypertension, Henry Ford Hospital, Detroit, MI, USA

6 Vanderbilt University School of Nursing, Nashville, TN, USA
The authors regret that the following errors occurred in the original published article. The corrected text, tables, and figure have been presented with this erratum.

In Abstract section, the second sentence should read, "A multi-site cross-sectional study was conducted among 366 dialysis subjects who completed the study."

In Measures section, the third paragraph should read, "The dependent variable was self-reported phosphate binder medication adherence assessed using the Morisky Medication Adherence Scale (MMAS) (Krousel-Wood et al., 2009; Morisky et al., 2008; Morisky \& DiMatteo, 2011). This is a widely used self-reported scale for medication adherence that has been previously adapted for phosphorus control (Joson et al., 2015; Umeukeje et al., 2015). The MMAS-8 total score ranges from 0 to 8 , with scores of less than 6 indicating low adherence, 6 to less than 8 indicating medium adherence, and a score of 8 indicating high adherence. This 8 -item summated rating scale demonstrated good internal consistency (Cronbach's $\alpha=0.83$ ) and good concurrent and predictive validity in assessing medication adherence in subjects with chronic diseases, such as hypertension (Morisky et al., 2008)."

In Results section, the first paragraph should read, "A multi-site cross-sectional study was conducted among 366 dialysis subjects who completed the study. There were 256 potential subjects screened at VUMC out of which 204 completed the study; 109 potential subjects were screened at HFH out of which 99 completed the study".

In the same section, the second paragraph should read, "The average age of the subjects was 55 years (SD 15.3), $49 \%$ were men and $64 \%$ were non-White. Most of the subjects (79\%) received hemodialysis. Lower health literacy was found in $34 \%$ of the subjects, and $47 \%$ reported having high school education or less. Twenty-seven percent of the subjects had private health insurance, and only 
$15 \%$ of the subjects reported having excellent or very good health. The mean (SD) MMAS score was 5.2 (1.8), and the mean (SD) serum phosphorus level was 5.4 (1.6) $\mathrm{mg} / \mathrm{dL}$. Details of key subject characteristics are provided in Table 2."

In subsection, "Health Care Climate Scores," the second paragraph should read, "Subjects with higher HCC scores were less likely to be in-center hemodialysis subjects (71 vs. $81 \% ; p=0.05$ ). There were no observed significant differences in the proportion of subjects with low health literacy or education level by HCC category. Subjects with private health insurance were more likely to be in the higher HCC score group than the lower HCC score group (41 vs. $23 \% ; p<0.01$ ), and there were significant differences in HCC scores by site (Table 2)."

In the section, "HCC scores and medication adherence," the first paragraph should read, "The mean (SD) self-reported phosphate binder medication adherence score was 5.2 (1.8), and this showed a trend for a positive association with HCC score in unadjusted linear regression analysis ( $\beta$ [95\% CI]: $0.11[-0.02-0.23] ; p=0.09)$. The mean medication adherence score for the subjects in the higher HCC score group was higher than that of the subjects in the lower HCC score group [5.5(1.7) vs. 5.2(1.9); $p=0.08$ ]. This association was stronger, and significant, after adjusting for age, race, gender, study site, dialysis modality, and type of insurance $\beta$ [95\% CI]: 0.17 [0.05-0.30]; $p=0.007$ ) (Table 3)."

Following this, the first paragraph of the section, "HCC scores, medication adherence, and phosphorus control" should read, "The mean (SD) serum phosphorus level for all subjects was $5.4 \mathrm{mg} / \mathrm{dL}(1.6 \mathrm{mg} / \mathrm{dL})$, representing that many achieved target phosphorus levels with the upper limit often identified as $5.5 \mathrm{mg} / \mathrm{dL}$ (National Kidney Foundation, 2003). In a linear regression analysis, medication adherence was strongly associated with serum phosphorus level ( $\beta$ [95\% CI]: $-0.22[-0.31$ to -0.13$]$; $p<0.001)$ even after adjusting for age, gender, race, study site, private insurance, dialysis type, and HCC score $(\beta$ $[95 \% \mathrm{CI}]:-0.16[-0.25$ to -0.07$] ; \quad p<0.001)$ (Table 3)."

In Acknowledgement section, the below paragraph should be included,

The MMAS (8-item) content, name, and trademarks are protected by US copyright and trademark laws. Permission for use of the scale and its coding is required. A license agreement is available from Donald E. Morisky, ScD, ScM, MSPH, 14725 NE 20th St Bellevue, WA 98007, USA; dmorisky@gmail.com.

Additional References:

Krousel-Wood, M. A., Islam T., Webber, L. S., Re, R. S., Morisky, D. E., \& Muntner, P. (2009). New medication adherence scale versus pharmacy fill rates in seniors with hypertension. American Journal of Managed Care, 15(1), 59-66.

Morisky, D. E., \& DiMatteo, M. R. (2011). Improving the measurement of self-reported medication nonadherence: Final response. Journal of Clinical Epidemiology, 64, 262-263.

The authors thank Dr. Donald E. Morisky for reviewing and approving this erratum. They appreciate the opportunity to revise their analyses, sincerely regret any confusion this may have caused and again are grateful for the chance to amend this report.

Table 1 Health Care Climate Scale items

\begin{tabular}{llllll}
\hline Item \# & $\begin{array}{l}\text { Male } \\
\text { Mean (SD) }\end{array}$ & $\begin{array}{l}\text { Female } \\
\text { Mean (SD) }\end{array}$ & $\begin{array}{l}\text { White } \\
\text { Mean (SD) }\end{array}$ & $\begin{array}{l}\text { Non-white } \\
\text { Mean (SD) }\end{array}$ \\
\hline HCC1 & $5.2(2.1)$ & $5.0(2.2)$ & $5.7(1.6)$ & $4.7(2.3)$ & $\begin{array}{l}\text { Overall } \\
\text { Mean (SD) }\end{array}$ \\
HCC2 & $5.3(2.0)$ & $5.3(1.9)$ & $5.8(1.6)$ & $5.0(2.0)$ & $5.1(2.1)$ \\
HCC3 & $5.6(1.7)$ & $5.8(1.7)$ & $5.9(1.5)$ & $5.6(1.8)$ & $5.3(1.9)$ \\
HCC4 & $5.4(1.9)$ & $5.6(1.8)$ & $5.8(1.6)$ & $6.1(1.5)$ & $5.5(1.8)$ \\
HCC5 & $6.1(1.5)$ & $6.1(1.4)$ & $6.1(1.3)$ & $5.2(2.0)$ & $5.1(1.5)$ \\
HCC6 & $5.4(1.9)$ & $5.5(1.9)$ & $5.9(1.6)$ & $5.3(1.6)$ & $5.5(1.9)$ \\
Total HCC & $5.5(1.5)$ & $5.6(1.5)$ & & & $5.5(1.5)$ \\
\hline
\end{tabular}


Table 2 Patient characteristics for total sample and by Health Care Climate Scale score categories

\begin{tabular}{|c|c|c|c|c|}
\hline Variables & All subjects & $\begin{array}{l}\text { Lower } \\
\text { HCC score } \\
N=278(76 \%)\end{array}$ & $\begin{array}{l}\text { Higher } \\
\text { HCC score } \\
N=88(24 \%)\end{array}$ & $p$ value \\
\hline \multicolumn{5}{|l|}{ Demographics } \\
\hline Age (mean, SD) & $55(15.3)$ & $55(15.5)$ & $56(14.9)$ & 0.56 \\
\hline$\%$ Male & $49(\mathrm{n}=180)$ & $50(\mathrm{n}=139)$ & $47(n=41)$ & 0.58 \\
\hline$\%$ Non-white & $64(\mathrm{n}=233)$ & $67(\mathrm{n}=187)$ & $52(\mathrm{n}=46)$ & 0.01 \\
\hline$\%$ In-center hemodialysis & $79(\mathrm{n}=286)$ & $81(n=223)$ & $71(\mathrm{n}=63)$ & 0.05 \\
\hline$\%$ Low health literacy & $34(\mathrm{n}=124)$ & $34(\mathrm{n}=95)$ & $33(\mathrm{n}=29)$ & 0.85 \\
\hline$\%$ High school education or less & $47(\mathrm{n}=173)$ & $46(n=128)$ & $51(\mathrm{n}=45)$ & 0.40 \\
\hline$\%$ Private health insurance & $27(\mathrm{n}=99)$ & $23(\mathrm{n}=63)$ & $41(n=36)$ & 0.001 \\
\hline \multicolumn{5}{|l|}{$\%$ Subject enrollment per site } \\
\hline Vanderbilt University Medical Center & $56(\mathrm{n}=204)$ & $51(\mathrm{n}=142)$ & $70(\mathrm{n}=62)$ & $<0.001$ \\
\hline Henry Ford Hospital & $27(\mathrm{n}=99)$ & $35(\mathrm{n}=96)$ & $3(n=3)$ & \\
\hline CentraCare Health (MN) & $17(\mathrm{n}=63)$ & $14(\mathrm{n}=40)$ & $26(\mathrm{n}=23)$ & \\
\hline \multicolumn{5}{|l|}{ Outcomes } \\
\hline Medication adherence $($ mean, SD) $($ range $=0-8)$ & $5.2(1.8)$ & $5.2(1.9)$ & $5.5(1.7)$ & 0.08 \\
\hline Serum phosphorus level (mean, SD) & $5.4(1.6)$ & $5.4(1.6)$ & $5.7(1.7)$ & 0.11 \\
\hline
\end{tabular}

Bold values indicate statistical significance $(p<0.05)$; HCC Health Care Climate Scale; $M N$ Minnesota

The MMAS (8-item) content, name, and trademarks are protected by US copyright and trademark laws. Permission for use of the scale and its coding is required. A license agreement is available from Donald E. Morisky, ScD, ScM, MSPH, 14725 NE 20th St Bellevue, WA 98007, USA; dmorisky@gmail.com

Table 3 Adjusted regression coefficients for medication adherence and phosphorus control

\begin{tabular}{|c|c|c|c|c|}
\hline \multirow[t]{2}{*}{ Variable } & \multicolumn{2}{|c|}{ Medication adherence $(\mathrm{N}=365)$} & \multicolumn{2}{|c|}{ Phosphorus control $(\mathrm{N}=363)$} \\
\hline & $\beta(95 \% \mathrm{CI})$ & $p$ value & $\beta(95 \% \mathrm{CI})$ & $p$ value \\
\hline HCC score & $0.17(0.05-0.30)$ & 0.007 & $0.07(-0.03$ to 0.18$)$ & 0.17 \\
\hline Age & $0.03(0.02-0.04)$ & $<0.001$ & $-0.03(-0.04$ to -0.02$)$ & $<\mathbf{0 . 0 0 1}$ \\
\hline Race (Ref: white) & $0.24(-0.16$ to 0.65$)$ & 0.24 & $-0.55(-0.90$ to -0.20$)$ & 0.002 \\
\hline Site & $0.32(0.07$ to 0.58$)$ & 0.01 & $-0.05(-0.27$ to 0.17$)$ & 0.64 \\
\hline Gender (Ref: female) & $-0.08(-0.45$ to 0.28$)$ & 0.64 & $-0.04(-0.35$ to 0.27$)$ & 0.78 \\
\hline Private insurance & $-0.11(-0.54$ to 0.31$)$ & 0.60 & $0.32(-0.04$ to 0.68$)$ & 0.08 \\
\hline Dialysis modality (Ref: peritoneal dialysis) & $0.37(-0.19$ to 0.93$)$ & 0.19 & $0.07(-0.40$ to 0.55$)$ & 0.76 \\
\hline Medication adherence score & & & $-0.16(-0.25$ to -0.07$)$ & $<0.001$ \\
\hline
\end{tabular}

Bold values indicate statistical significance $(p<0.05)$; HCC Health Care Climate Scale

The MMAS (8-item) content, name, and trademarks are protected by US copyright and trademark laws. Permission for use of the scale and its coding is required. A license agreement is available from Donald E. Morisky, ScD, ScM, MSPH, 14725 NE 20th St Bellevue, WA 98007, USA; dmorisky@gmail.com 
Fig. 1 A revised study flow diagram is presented below.

Phosphate Binder Adherence Multi-Site Study

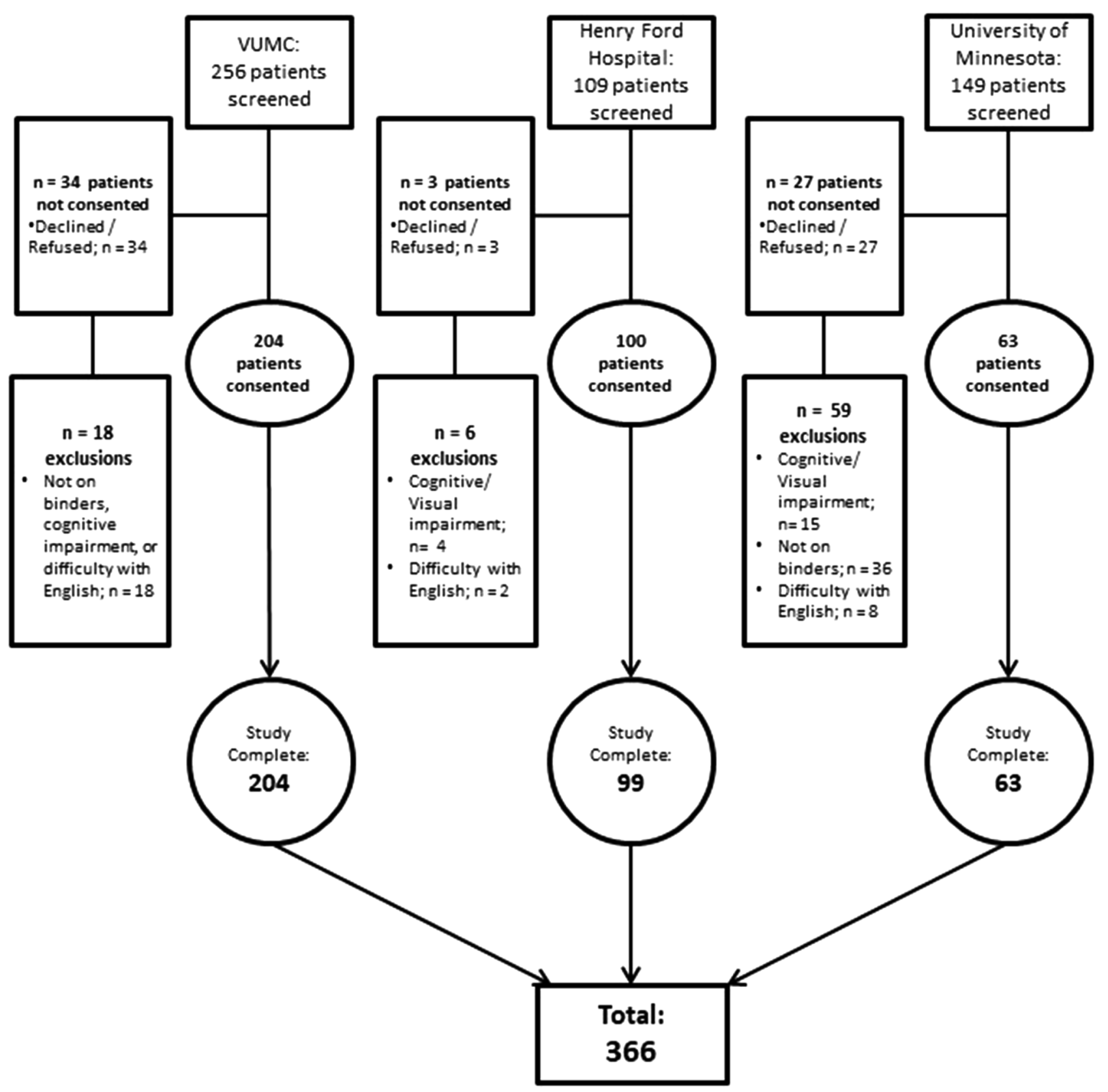

